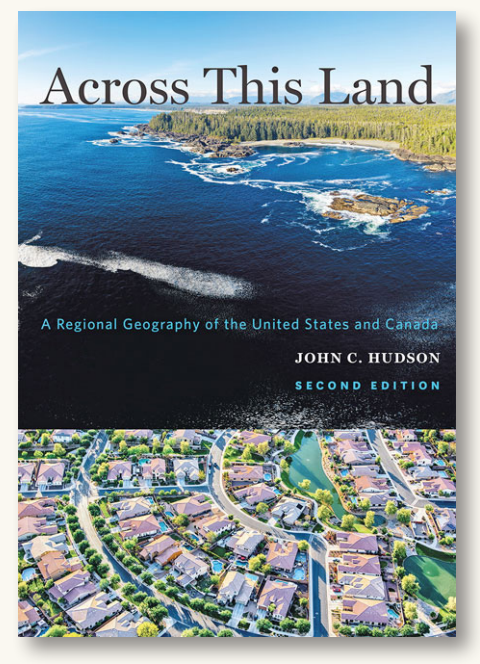

\title{
ACROSS THIS LAND: A REGIONAL GEOGRAPHY OF THE UNITED STATES AND CANADA, SECOND EDITION
}

By John C. Hudson

Johns Hopkins University Press, 2020

529 pages

Paperback: \$69.95, ISBN 978-1-4214-3758-3

Review by: Russell S. Kirby (he/him), University of South Florida

TEXTBOOKS ON REgIONAL GEOGRAPHY were once a staple of undergraduate geography education. There were several to choose from in the 1970 s, most covering a single continent or country, and all with a familiar, uniform organization and approach. Most focused on the relatively current scene, with recent photographs and illustrations, statistical tables from government data sources such as the US Census Bureau, and text written in a style more like an encyclopedia than narrative prose. Little changed over the next few decades. There were plenty of choices, but little variety or excitement, and although the field has thinned a bit in the intervening years, the reading has hardly gotten livelier.

Imagine my joy then, in 2002, when I received a review copy of the first edition of Hudson's Across This Land. This regional geography of North America, focused on the United States and Canada (though not Mexico), provided a refreshing contrast to the available offerings, with an idiosyncratic organization reflective of the author's appreciation for physical and historical geography, and engagingly integrating academic research with his personal experience teaching courses on this subject for thirty years.

Move the clock forward to today, and we now have a second edition of this textbook. Hudson has changed none of the features that made the initial book so distinctive. As previously, the text is separated into ten regionally focused Parts, each comprised of two or three thematic chapters, of which there are twenty-seven in total. In turn, each chapter addresses a varying number of particular topics. The ten Parts- "Atlantic Canada and Quebec," "The Northeast," "The Upland South," "The Lowland South," "The Middle West," "The Central Plains," "The Western Plains and Rocky Mountains," "The Intermountain West," "The North," and "The Pacific Realm"-are grouped primarily by physiography or major patterns of economic activity. Meanwhile, the focus of the chapters is on areas with distinctive features in their history, social fabric, or patterns of land use: for example, "Chapter 19. The Northern Rocky Mountains and the Columbia-Snake Plateau," in "Part VIII. The Intermountain West." While a few are restricted to a single political/administrative unit (such as "Chapter 26. California"), or a group of units ("Chapter 3. The Maritimes"), this occurs only in places where the administrative unit broadly corresponds to some sort of homogeneous region.

"Chapter 15. Prairie Wheat Lands," can serve as an example of the organization and focus of the others. It consists of eight topics - the Central Plains environment, the winter and the summer wheat regions, the Red River valley, the Parkland belt, the Prairie Provinces, Alberta's oil industry, and the Peace River district-each receiving three or four pages, including illustrations, and the chapter concludes with a brief list of key references.

What makes this textbook such an intriguing read is Hudson's ability to capture the "sense of place" that contributes to the distinctiveness of the various North 
American regions. The basic information found in an instructor-led course on the geography of the United States is there, but much more than that is captured in these pages. Distinctive land use patterns, housing, and other cultural landscape features are mentioned throughout the text, accompanied by useful maps and illustrated with judiciously selected photographs. One might be tempted to say that this book has it all.

Tempted, perhaps, but there are some shortcomings. It is noticeable that, while Hudson pays some attention to the geography of native peoples, his primary focus is squarely on the settlement following European colonization. His references, too, could be more comprehensive, comprised mostly of materials referenced in the previous edition with only minimal updating. While there is a chapter on Hawaii, and two pages on US Pacific island territories, Puerto Rico receives little coverage. Perhaps befitting a text organized around regions, broader themes in economic and population geography receive limited attention. For example, patterns of internal migration, differences in regional demographic composition, cultural differences in diet, linguistics, religion, and spatial aspects of structural racism are among the topics not discussed. But should they have been? Maybe, or maybe not. While the book does what it set out to do, for those readers wishing for more, most chapters have at least a dozen references for additional reading. Given the organizational framework for the book, Hudson does an admirable job weaving a complex tapestry of physiography, climate and meteorology, cultural landscapes, and key aspects of economic activity, while inserting historical tidbits along the way. An instructor teaching a course on regional geography could supplement this text with any of the topics I've mentioned-using readings, photographs, videos, and lecture materials - to round out the picture.

Across This Land is an excellent resource on the geography of North America. It is suitable for undergraduate courses, but easily stands on its own for the casual reader who wants to know more about the structures that tie the United States and Canada together as nations, and about the distinctive features of each complex regional tapestry. Any well-read North American should have read or have access to a copy, and it can be used by parents to inspire their children to realize that geography is more than memorization of lists of state capitals, major cities, rivers, and other physiographic features. Across This Land provides an effective introduction to the field of geography, through the lens of a well-traveled, highly accomplished scholar and educator. I heartily recommend it to all! 